\title{
The effect of nasal breathing on the exercise induced bronchospasm in children with allergic asthma and rhinitis
}

\author{
Mirjana Turkalj ${ }^{1 *}$, Martina Canaki ${ }^{2}$, Robert Magdic ${ }^{2}$, Marcel Lipej ${ }^{2}$, Sandra Bulat ${ }^{2}$, Jelena Zivkovic ${ }^{2}$, Davor Plavec ${ }^{2}$ \\ From 9th Symposium of Experimental Rhinology and Immunology of the Nose (SERIN 2013) \\ Leuven, Belgium. 21-23 March 2013
}

\section{Background}

Allergic rhinitis (AR) is very common in children and it affects $10-40 \%$ of children world-wide. Asthma and AR commonly coexist and we can find up to $30 \%$ of asthma in patients with AR and up to $90 \%$ of AR in patients with asthma. Moreover, these two disorders seem to influence each other's activity and intensity. Physical activity is commonly prescribed as a rehabilitation treatment for asthma in children although there is a high percentage of asthmatics with exercise-induced bronchospasm (EIB) at that age and recent studies show beneficial effects of aerobic training on allergic inflammation. EIB can be one of the reasons for low adherence to physical training. The aim of this study was to test if a nose clip during a 6 minute free running test changes the magnitude of EIB according to the severity of AR.

\section{Methods}

The study was conducted in 55 children (24 girls, mean age 12.6 yrs) with moderate persistent asthma and AR in an Asthma Camp, at island Lošinj. Their asthma was controlled under their regular treatment and they were daily participating in an aerobic fitness program. They were divided in two subgroups according to the median of intensity of their nasal symptoms (less nasal symptoms LNS; more nasal symptoms - MNS). Spirometry was performed before, 3' and 20' after 2 exercises (6 minutes free running with and without a nose clip) done a day apart.

\section{Results}

Two subgroups (LNS and MNS) were not significantly different according to their demographic characteristics, sensitization profile, asthma control, lung function and exhaled NO measurements and physical fitness ( $p>0.05$ for all). There was a significantly greater fall in FEV1 3' after exercise with a nose clip in the LNS subgroup than in the MNS subgroup $(\mathrm{p}<0.001)$ and compared to testing without the nose clip (LNS, $\mathrm{p}=0.009$; MNS, $\mathrm{p}=0.010)$. Contrary to the testing with the nose clip there were no significant differences in the FEV1 fall after exercise when the same patients were tested without the nose clip during exercise $(\mathrm{p}>0.68)$.

\section{Conclusion}

It seems that regular mouth breathing due to nasal congestion somehow protects patients with asthma and AR from EIB.

\section{Author details}

${ }^{1}$ Children's Hospital Srebrnjak, Zagreb, Croatia. ${ }^{2}$ Children's Hospital Srebrnjak, Allergy Department, Zagreb, Croatia.

Published: 16 July 2013

doi:10.1186/2045-7022-3-S2-P7

Cite this article as: Turkalj et al:: The effect of nasal breathing on the exercise induced bronchospasm in children with allergic asthma and rhinitis. Clinical and Translational Allergy 2013 3(Suppl 2):P7.

${ }^{1}$ Children's Hospital Srebrnjak, Zagreb, Croatia

Full list of author information is available at the end of the article

(c) 2013 Turkalj et al; licensee BioMed Central Ltd. This is an Open Access article distributed under the terms of the Creative Commons 